\title{
Oportunidades e Ameaças na Indústria do Turismo: análise estratégica relacional do caso dos hotéis líderes da cidade do Rio de Janeiro
}

\author{
Opportunities and Threats in the Tourism Industry: relational strategic analysis of the case \\ of leading hotels of the city of Rio de Janeiro
}

\section{Oportunidades y Amenazas en la Industria Turística: análisis estratégica relacional de los hoteles líderes de la ciudad de Rio de Janeiro}

\author{
Mariana de Queiroz Brunelli ${ }^{1}$ \\ T. Diana L. van Aduard de Macedo-Soares ${ }^{2}$
}

\begin{abstract}
Resumo
No contexto competitivo contemporâneo, para serem assertivas, as organizações, inclusive as atuantes no turismo, precisam levar em consideração nas suas análises e tomadas de decisão não apenas as implicações de fatores relacionados à indústria de atuação e aos recursos internos das firmas, mas também aos seus relacionamentos com outras organizações. Este artigo apresenta os resultados de uma pesquisa que, à luz da reflexão acima, aplicou um arcabouço de análise estratégica relacional ao caso dos hotéis líderes da cidade do Rio de Janeiro. A pesquisa objetivou analisar as oportunidades e as ameaças criadas pelas alianças estratégicas destes hotéis considerando não somente seus objetivos de competir no cenário global, mas também seus papéis no desenvolvimento do próprio destino turístico. Para isso, foram analisados tanto fatores não-relacionais (macroambientais e atores estratégicos chaves no desempenho de seus papéis tradicionais) quanto fatores relacionais (pertinentes aos relacionamentos, do tipo alianças, e à rede formada por estes) para identificar as implicações estratégicas mais significativas no nível da indústria. Os resultados mostraram que ao incluir na análise estratégica os fatores relacionais, a maioria das ameaças reveladas é neutralizada, fornecendo novos insights para o processo de decisão gerencial. Além disso, mostrou também o potencial dos hotéis estudados de aproveitar as oportunidades constituídas por suas alianças, no sentido de contribuírem para o desenvolvimento socioeconômico da cidade por meio da sua atuação como atores centrais na rede de relacionamentos da indústria do turismo.
\end{abstract}

Palavras-chave: turismo; estratégia; alianças; hotéis.

\footnotetext{
1 Mestre. Pesquisadora Visitante do Departamento de Administração da PUC-Rio. E-mail: maribrunelli@gmail.com.

2 Ph.D. Professora Titular do Departamento de Administração da PUC-Rio. E-mail: tdiana.vanaduardmacedosoares@gmail.com.
} 


\begin{abstract}
In the contemporary competitive environment, to be assertive, organizations, including those working in tourism, must take into account in their analysis and decision-making not only the implications of factors related to industry performance and internal resources of firms, but also to their relationships with other organizations. This article presents the results of a research that, in light of the discussion above, applied a relational framework for strategic analysis to the case of leading hotels of the city of Rio de Janeiro. The paper analyzes the opportunities and threats created by strategic alliances of these hotels not only considering their goals to compete on the global stage, but also their own roles in the development of a tourist destination. For this, we analyzed both non-relational factors (macro environmental and key strategic players in the performance of their traditional roles) and relational factors (pertaining to relationships, like alliances, and the network composed of these) to identify the most significant strategic implications at industry level. The results showed that by including in the strategic analysis relational factors, most of the threat posed is neutralized, providing new insights into the management decision process. In addition, it also showed the potential of the studied hotels to seize the opportunities revealed by their alliances in order to contribute to the socioeconomic development of the city through its role as central actors in the network of relationships in the tourism industry.
\end{abstract}

Keywords: tourism; strategy; alliances; hotels.

\title{
Resumem
}

En el entorno competitivo actual, las organizaciones, incluidas las que trabajan en el turismo, deben tener en cuenta en el análisis y la toma de decisiones no sólo las consecuencias de los factores relacionados con el desempeño de la industria y los recursos internos de las empresas, sino también a sus relaciones con otras organizaciones. Este artículo presenta los resultados de una investigación que, a la luz de la discusión anterior, aplica un marco relacional para el análisis estratégico del caso de los principales hoteles de la ciudad de Río de Janeiro. El documento analiza las oportunidades y amenazas creadas por las alianzas estratégicas de estos hoteles no sólo teniendo en cuenta sus objetivos de competir en el contexto global, sino también su propio papel en el desarrollo de un destino turístico. Para eso, se analizaron los factores no-relacionales (macro ambientales y actores estratégicos en el desempeño de sus funciones tradicionales) y los factores relacionales (relativos a las relaciones, como las alianzas, y la red integrada de estos) para identificar las implicaciones estratégicas más importantes en nivel de la industria. Los resultados mostraron que al incluir en el análisis los factores relacionales estratégicos, la mayoría de las amenazas se neutralizan, proporcionando nuevos conocimientos sobre el proceso de decisiones gerenciales. Además, también se mostró el potencial de los hoteles estudiados para aprovechar las oportunidades que se reveló por sus alianzas con el fin de contribuir al desarrollo socioeconómico de la ciudad a través de su papel como actores centrales en la red de relaciones en la industria del turismo. Palabras clave: turismo; estrategia; alianzas; hoteles. 


\section{Introdução}

O desenvolvimento de um destino turístico está relacionado à capacidade de suas empresas atuarem de maneira estrategicamente proativa (CLAVER-CORTÉS; MOLINA-AZORÍN; PEREIRA-MOLINER, 2007). Isso porque se um destino é competitivo, ele atrai mais turistas, o que aumenta os níveis de lucratividade das empresas que atuam neste mercado. Além disso, se as empresas do destino forem proativas estrategicamente, elas investirão mais dinheiro em treinamento, qualidade, gestão ambiental etc., contribuindo assim para reforçar a capacidade do destino de competir (CLAVER-CORTÉS et al., 2007).

No entanto, no contexto competitivo global contemporâneo, para serem assertivas, as organizações, inclusive as que atuam na indústria do turismo, precisam levar em consideração, nas análises e tomadas de decisão, não apenas as implicações de fatores relacionados à indústria de atuação e aos recursos internos das firmas, mas também aos seus relacionamentos com outras organizações (MACEDO-SOARES, 2011).

Este artigo apresenta os resultados de uma pesquisa que, à luz das reflexões acima, aplicou um arcabouço de análise estratégica relacional ao caso dos hotéis líderes da cidade do Rio de Janeiro, um dos destinos turísticos mais famosos do Brasil, escolhido para receber o jogo final da Copa do Mundo de Futebol de 2014 e para ser sede dos Jogos Olímpicos de 2016.

Nesse sentido, a pesquisa aqui reportada buscou analisar as oportunidades e as ameaças criadas pelas alianças estratégicas destes hotéis considerando não somente seus objetivos de competir no cenário global, mas também seus papéis no desenvolvimento do próprio destino turístico. Os hotéis foram escolhidos como as empresas turísticas a serem estudadas porque são considerados um dos principais atores da macrorrede formada pela indústria do turismo (SCOTT; BAGGIO; COOPER, 2008; TIMUR; GETZ, 2008; MARCH; WILKINSON, 2009). Para alcançar seu objetivo, a pesquisa empreendeu uma avaliação estratégica global das empresas estudadas com relação tanto aos fatores não-relacionais (macroambientais) e aos pertinentes aos atores estratégicos chaves no desempenho de seus papéis tradicionais quanto aos fatores relacionais - pertinentes aos relacionamentos, do tipo alianças, e à rede formada por estes -, para identificar suas implicações estratégicas mais significativas no nível da indústria. Esta avaliação foi realizada com auxílio do arcabouço "Global SNA” de análise estratégica relacional desenvolvido por Macedo-Soares (2011). 
Este artigo está dividido em seis seções, incluindo esta introdução. A segunda seção fornece uma síntese da revisão de literatura sobre redes e alianças estratégicas na indústria do turismo e sobre o setor hoteleiro, assim como descreve o arcabouço de análise estratégica relacional adotado. A terceira seção apresenta a metodologia da pesquisa empírica. Nas duas seções seguintes os resultados da pesquisa são apresentados e discutidos, respectivamente. Na sexta e última seção, destacam-se as lições principais da pesquisa e fornecem-se algumas recomendações para investigações futuras.

\section{Fundamentação Teórica}

\subsection{Redes e alianças estratégicas na indústria do turismo}

Para Tremblay (1998), a perspectiva de rede é o paradigma teórico mais adequado para a compreensão da indústria do turismo. A afirmação desse autor é baseada em sua análise das características dessa indústria enquanto um sistema dinâmico, constituído por atividades heterogêneas, interdependentes e, na sua maioria, complementares. Tal visão é compartilhada por Scott et al. (2008) quando afirmam que o turismo sempre foi uma indústria em rede.

A constatação desses autores parece ainda mais relevante no contexto atual de grande turbulência em relação às tendências do ambiente competitivo e globalizado. Segundo Tremblay (1998), as empresas turísticas estão cada vez mais gerenciando as incertezas por meio do estabelecimento de redes de ligações que englobam trocas de informação, construção de canais de comunicação confiáveis e planejamento conjunto.

March e Wilkinson (2009), por sua vez, afirmam que no turismo a criação de valor para os clientes acontece por meio de uma complexa rede de interações entre atores interdependentes. Scott et al. (2008) complementam essa ideia ao observarem que o destino turístico é composto por um grupo de fornecedores independentes articulados espontaneamente para entregar o produto turístico. Nesse contexto, os produtos do destino turístico são produzidos pela agregação de diferentes elementos no momento do consumo para providenciar a experiência total do cliente (WANG; KRAKOVER, 2008).

As características do turismo identificadas acima reforçam a necessidade do desenvolvimento de relações de cooperação entre empresas e organizações para agregar recursos e desenvolver um comprometimento mútuo com o objetivo comum de atrair mais visitantes para o destino (WANG; KRAKOVER, 2008). As motivações por trás dos relacionamentos colaborativos no 
turismo podem variar substancialmente e ter objetivos tão diversos quanto econômicos, estratégicos, sociais e de aprendizagem (WANG; FESENMAIER, 2007).

Quando esses relacionamentos formam uma rede de cooperação, as empresas obtêm vantagens competitivas por compartilhar conhecimento, recursos, mercados e tecnologias (NOVELLI; SCHIMITZ; SPENCER, 2006; SCOTT et al., 2008; TIMUR; GETZ, 2008; MARCH; WILKINSON, 2009). Outro importante papel dessas redes é minimizar os custos de transação e explorar economias de escala e escopo, dividindo riscos e dando acesso a recursos complementares (ERKUS-OZTURK, 2009).

O sucesso de uma rede de cooperação pode levar empresas a desenvolverem relacionamentos mais formais como alianças estratégicas para compartilhamento ou co-desenvolvimento de produtos e serviços (NOVELLI et al., 2006). Dentre as alianças estratégicas mais pertinentes à indústria do turismo, Pansiri (2008) destaca as seguintes: joint ventures; compartilhamento de ativos; compartilhamento de marcas; franquias e licenciamentos; acordos de marketing e de distribuição; vendas e distribuição conjunta; compartilhamento de informações e tecnologia; acordos para compras conjuntas e compartilhamento de equipamentos.

Para Novelli e. al. (2006), as alianças estratégicas geram melhoria na qualidade dos serviços, aumento da visibilidade dos destinos e abrem oportunidades para atividades de "crossmarketing" com outros aglomerados de empresas.

As visões dos autores apresentados nesta seção sugerem fortemente que a perspectiva de rede é particularmente apropriada para conduzir pesquisas em uma indústria multidisciplinar como a do turismo. De fato, é difícil negar que “... a indústria do turismo fornece um contexto ideal para estudos sobre redes" (SCOTT et al., 2008, p.1, tradução nossa). Ao permitir a análise não apenas de sua estrutura, mas de suas interconexões, a perspectiva de rede pode contribuir para uma compreensão mais profunda da indústria do turismo (SCOTT et al., 2008). Além disso, conforme exposto, é possível revelar oportunidades e ameaças, assim como forças e fraquezas do destino sob um novo prisma relacional.

\subsection{Redes e alianças estratégicas no setor hoteleiro}

É na literatura sobre internacionalização de empresas hoteleiras que se encontra a maioria das referências sobre as alianças e redes estratégicas existentes nesse setor. Entretanto, nessas pesquisas, as alianças e redes são citadas como meios usados nas estratégias de expansão dos 
hotéis. A estrutura e a composição dos laços, assim como as implicações de suas características não são analisadas em profundidade.

Segundo Johnson e Vanetti (2005), devido à diversidade do turismo e as dificuldades de lançamento de produtos intermediários nos mercados, há incentivos significativos para as empresas hoteleiras se internacionalizarem. Essa idéia é corroborada por Ayoun e Moreo (2008) quando afirmam que a internacionalização de hotéis tem se acelerado a uma taxa sem precedentes nas últimas décadas, com muitas empresas se engajando em redes de negócio, com um aumento da quantidade de fusões e aquisições no setor e com as alianças estratégicas internacionais configurando uma tendência crescente. A literatura recente defende, inclusive, que a internacionalização de empresas no setor hoteleiro não é dirigida à exportação, mas sim, cada vez mais, devido ao uso crescente de alianças estratégicas, trata-se de um fenômeno de integração (JOHNSON; VANETTI, 2005).

De uma maneira geral, pode-se dizer que, no processo de internacionalização das empresas hoteleiras, a opção por modelos não baseados em investimentos de propriedade ("nonequity") tem sido mais recorrente (CONTRACTOR; KUNDU, 1998; CHEN; DIMOU, 2005; JOHNSON; VANETTI, 2005). Para Contractor e Kundu (1998), isso é comum em setores de serviços, tais como o hoteleiro, onde elementos de capital intensivo (como imóveis) podem ser separados de elementos de especialização do conhecimento ou de gestão da competitividade.

Nesse sentido, as formas de expansão "non-equity" seriam propícias ao setor hoteleiro devido a certas características de suas empresas, como: a vontade de transferência de conhecimento, a facilidade de codificação dos sistemas de gestão e a maior facilidade no controle que pode ser exercido, por exemplo, sobre as franquias, devido à fácil codificação das competências e sistemas gerenciais e de reservas (JOHNSON; VANETTI, 2005).

No que tange aos tipos de alianças estratégicas mais utilizadas pelas empresas hoteleiras para se internacionalizarem, de acordo com a literatura, destacam-se os contratos de gestão, de licenciamento e as franquias (CONTRACTOR; KUNDU, 1998; CHEN; DIMOU, 2005; JOHNSON; VANETTI, 2005; MARTINEZ; ESQUIVEL, 2006).

Os acordos de licenciamento preconizam um contrato de transferência de direitos, por meio do qual se autoriza, dentro de determinadas circunstancias, usar, por exemplo, uma marca em troca de um pagamento inicial ou periódico (MARTINEZ; ESQUIVEL, 2006). A franquia, 
em seu turno, segundo Martinez e Esquivel (2006), é uma variante do acordo de licenciamento, porém com maior amplitude em termos de uso da marca, padrões de operação e acesso a recursos. Para esses autores, esse modelo pode ser uma oportunidade para empresas pequenas e médias que não dispõem de muito capital, mas que tenham desenvolvidos processos competitivos, pois permite maior rapidez para se conseguir uma ampla rede comercial, menor rejeição dos governos locais e menores restrições legais.

Por outro lado, o franqueador, por não controlar a operação do empreendimento, assume um perfil de risco em termos de imagem e prestígio, assim como, em determinado momento, pode perceber o franqueado como um competidor (MARTINEZ; ESQUIVEL, 2006). Todavia, é esperado que a empresa hoteleira internacional (franqueador) tenha ao menos algumas economias de escala em nível global - logística, fornecimento, design arquitetônico, reservas, treinamento e reconhecimento de marca (CONTRACTOR; KUNDU, 1998).

Outro tipo de aliança estratégica, citado na literatura, é o contrato de gestão. No setor hoteleiro, o contrato de gestão é um acordo entre uma empresa de gestão de hotéis e outra proprietária, por meio do qual a empresa de gestão - em geral pertencente a um grupo internacional forte - explora a operação do dia-a-dia do hotel em troca de uma taxa financeira (MARTINEZ, ESQUIVEL, 2006; CONTRACTOR; KUNDU, 1998).

Segundo Martinez e Esquivel (2006), no contrato de gestão, o proprietário do estabelecimento não toma as decisões operacionais, mas assume responsabilidade pelo capital necessário, pelos gastos e dívidas e, por tanto, assume todos os riscos da operação e a responsabilidade do capital circulante. Não obstante, o controle estratégico de longo prazo nesse tipo de aliança, de acordo com Contractor e Kundu (1998), é menor do que em joint ventures.

\subsection{Arcabouço de análise estratégica relacional}

O arcabouço de análise estratégica adotado por esta pesquisa é o Global Strategic Network Analysis Framework (Global SNA) desenvolvido por Macedo-Soares (2002, 2011), adaptado por esta pesquisa à indústria do turismo. Esse segue a definição de alianças de Gulati (1998) ressaltando que, para serem estratégicas, elas precisam contribuir diretamente para a vantagem competitiva da empresa (MACEDO-SOARES, 2002). A tipologia de alianças e ligações em função do seu grau de intensidade/ interdependência, de acordo com Contractor e Lorange (1988), Parise (2000) e Nohia e Garcia-Pont (1991) é adotado, onde fusões e aquisições são as ligações mais intensas e acordos/parcerias as menos intensas. Esta tipologia 
foi adaptada à indústria do turismo, com base nos autores acessados na revisão de literatura exposta.

O conceito de redes estratégicas adotado baseia-se em Gulati, Nohia e Zaheer (2000) de acordo com os quais três dimensões de rede são analisadas, no nível da indústria: 1) Estrutura da Rede - densidade, escopo, centralidade; (2) Composição de Rede - identidade/status dos parceiros e acesso aos recursos; (3) Modalidade dos Laços - força de conexões (forte/fraca) e da natureza dos vínculos (colaborativa/oportunistas).

O Global SNA pode ser utilizado para analisar a rede de relacionamentos de uma empresa focal, denominada ego-rede (MACEDO-SOARES, 2002) ou, ainda, a rede de alianças formada por empresas de um mesmo grupo estratégico - macro ego-rede -, conforme foi realizado por esta pesquisa (MACEDO-SOARES; MENDONÇA, 2010). Para a definição de grupo estratégico utilizaram-se as definições de Cool e Schendel (1987), que o conceituam como um conjunto de empresas competindo em uma mesma indústria à base de combinações semelhantes de escopo e recursos.

O Global SNA compreende três componentes principais: (1) uma metodologia para conduzir a análise estratégica relacional global; (2) listas de referências para guiar a coleta e a análise dos dados; e (3) um modelo conceitual para auxiliar no mapeamento da ego-rede da empresa focal ou da macro ego-rede do grupo estratégico dentro de suas redes de valor.

A metodologia do Global SNA compreende, resumidamente, as seguintes etapas a serem seguidas (MACEDO-SOARES, 2011) para os casos de análise no nível da indústria:

1. Caracterizar as estratégias competitivas e de mercado das empresas focais, usando as tipologias e construtos Mintzberg (1998) e Fahey e Randall (1998), bem como as de Bartlett e Ghoshal (1998), Harzing (2000) e Hitt, Ireland e Hoskisson (2009).

2. Identificar e analisar as implicações estratégicas dos fatores macro-ambientais de acordo com Austin (1990), assim como o papel dos atores chave da rede de valor das empresas (PORTER, 1980; BRANDENBURGER; NALEBUFF, 1996), no sentido de constituírem oportunidades e ameaças, reais ou potenciais.

3. Identificar e classificar as características das alianças estratégicas e outras ligações relevantes entre os parceiros que constituem a ego-rede das empresas focais, de acordo com as tipologias adotadas e, com base nas listas de referências, analisar as implicações dessas 
características no nível da indústria, no sentido de constituírem ameaças e oportunidades, tanto reais quanto potenciais.

As listas de referência para os fatores relacionais se baseiam principalmente em Gulati et. al. (2000) e Galaskiewicz e Zaheer (1999) e podem ser vistas por completo em Macedo-Soares (2011), onde constam construtos e indicadores pertinentes à alianças/redes globais. Por sua vez, o modelo conceitual do Global SNA Framework se concentra nas características da rede de ligações identificadas como estrategicamente significativas para a operação da empresa focal no cenário competitivo global (MACEDO-SOARES, 2011). Nesse sentido, a autora do modelo sugere o uso de tamanhos, formas e cores diferentes para a identificação das três dimensões relacionais enfocadas. Na Figura 1 é possível visualizar essa caracterização para a macro ego-rede dos hotéis líderes da cidade do Rio de Janeiro aqui pesquisados.

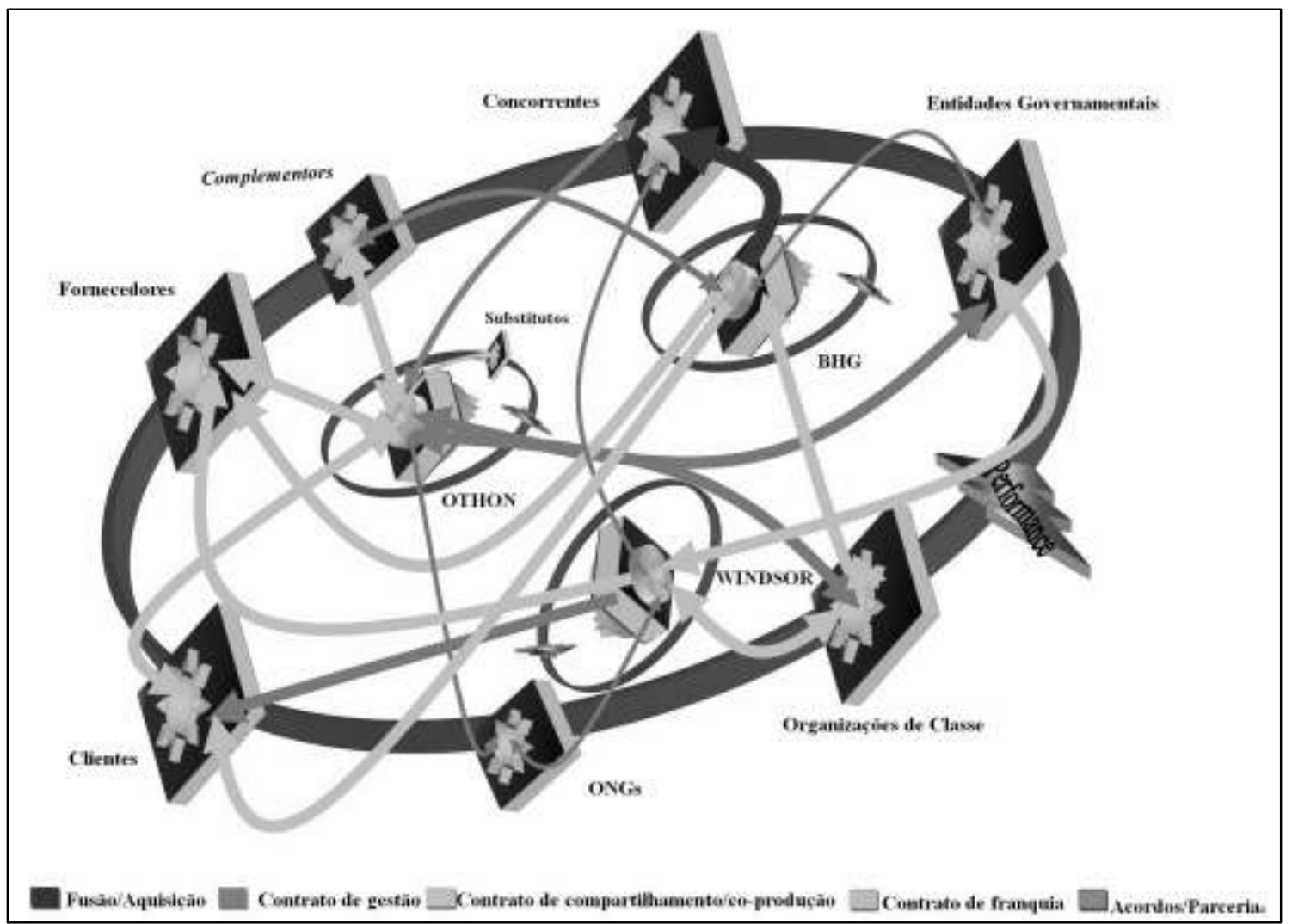

Figura 1 - Macro ego-rede dos Hotéis Líderes Pesquisados. 


\section{Metodologia}

Esta pesquisa exploratória foi operacionalizada como um estudo de casos devido esse método ser pertinente à geração de teoria a respeito de um fenômeno contemporâneo ainda pouco conhecido (YIN, 2005; EISENHARDT; GRAEBNER, 2007). Além disso, o método adotado é considerado adequado para investigações que utilizam a perspectiva relacional porque as redes de negócios são consideradas complexas e dinâmicas (HALINEN; TÖRNOOS, 2005; DREDGE, 2006).

Para empreender o estudo proposto, utilizou-se a estratégia de triangulação de dados (YIN, 2005), sendo eles coletados por meio de extensa investigação documental, levantamento de percepções dos gestores dos hotéis por meio de questionário estruturado, entrevista em profundidade com os principais dirigentes das empresas estudadas (Diretor de Marketing e Relações Institucionais da rede Windsor e Diretor Comercial da rede Othon) e com dirigente de organização representativa do setor hoteleiro (diretor associado da ABIH-RJ). O Brazilian Hospitality Group (BHG/Golden Tulip) não retornou às solicitações da pesquisa, por isso os dados relativos a essa empresa são exclusivamente documentais.

A unidade de análise da pesquisa foi limitada ao grupo estratégico dos hotéis líderes da cidade do Rio de Janeiro, em termos de número de hotéis e quartos oferecidos, que têm o perfil de turismo de negócios/eventos, notadamente as redes Windsor, Othon e BHG. As análises foram conduzidas a partir dos dados coletados na pesquisa documental, sendo estes confrontados com as respostas ao questionário e complementadas pelas informações levantadas nas entrevistas. Os resultados foram analisados à luz da literatura revista, especialmente, em relação aos construtos e indicadores apresentados pelo arcabouço teórico utilizado. Como esses já foram testados em outras pesquisas empíricas, acredita-se que a confiabilidade em relação aos resultados deste trabalho tenha sido aumentada.

\section{Resultados da Pesquisa}

\subsection{A indústria do turismo no Brasil e na cidade do Rio de Janeiro}

O Brasil detém apenas 3,4\% de participação no mercado turístico do continente americano (UNWTO, 2010). Entretanto, essa é uma indústria relevante para o país, pois é responsável 
por $3,2 \%$ de todas as receitas geradas com exportações de bens e serviços (MTUR, 2007) e por $15 \%$ do total de postos de trabalho do setor de serviços brasileiro (IBGE, 2008).

A principal motivação do turista estrangeiro para visitar o Brasil é lazer, representando quase o dobro daqueles que chegam ao país com fins de turismo de negócios (MTUR, 2010). Entretanto, em termos de gasto médio diário, o turista de negócios se mostra mais interessante para o Brasil, uma vez que gasta $68 \%$ a mais do que aqueles que têm o lazer como objetivo da viagem, permanecendo no país o mesmo tempo médio de 12 dias (MTUR, 2010).

Dentre os principais destinos turísticos brasileiros, a cidade do Rio de Janeiro é sem dúvida um dos maiores destaque. Para Gomes (2010), isso é reflexo de uma ampla oferta de aspectos e atrativos turísticos como a extensa faixa litorânea, com praias internacionalmente conhecidas e outros inúmeros atrativos naturais; as festas e manifestações de caráter folclórico e cultural; e o seu acervo arquitetônico, reflexo de uma rica perspectiva histórica.

Pelas razões citadas, a cidade do Rio de Janeiro continua a ser o principal destino para os turistas internacionais que visitam o Brasil por lazer e também é destaque na recepção de turistas do segmento de negócios, ficando atrás apenas da cidade de São Paulo (MTUR, 2010). Esses dados convergem com a importância da indústria do turismo para o Rio de Janeiro, que responde por $8,5 \%$ da economia total desta cidade brasileira (GOMES, 2010).

Desde que o Rio de Janeiro foi anunciado como sede das olimpíadas de 2016, com expectativas de investimento da ordem de R \$ 28,8 bilhões (GOLDBERG, 2010), as lideranças da cidade vêm mostrando empenho não só para consolidar uma imagem positiva do destino, mas principalmente, para desenvolver a sua infra-estrutura urbana e seus serviços turísticos, visando deixar um grande legado para os cidadãos (ROCHA, 2010).

O setor hoteleiro brasileiro, por sua vez, é considerado ainda muito fragmentado e, por isso, com oportunidades para uma rápida consolidação (EXAME.COM, 2010). Além disso, seguindo o padrão mundial, ele é composto tanto por empresas proprietárias de hotéis quanto por empresas administradoras, que fazem a gestão operacional dos mesmos. Tanto uma quanto outra pode desenvolver marcas próprias.

Para finalizar esse resumido panorama sobre a indústria do turismo e o setor hoteleiro brasileiro, destaca-se que, a partir dos dados do ranking nacional de hotéis (JONES LANG LASALLE HOTELS, 2010), utilizando-se os mesmos tipos de indicadores coletados por esta pesquisa em dados documentais, apurou-se que, na cidade do Rio de Janeiro, as empresas 
hoteleiras líderes são, nesta ordem: Windsor Hotéis, Accor, Othon Hotéis, BHG. Entretanto, a Accor não foi considerada no grupo estratégico estudado, devido ao seu posicionamento, no Brasil, estar voltado para hotéis econômicos (ALVARENGA, 2011).

\subsection{O caso múltiplo dos hotéis líderes da cidade do Rio de Janeiro}

Primeiramente, apresenta-se um breve histórico de atuação das empresas estudadas. Nota-se que essas informações foram retiradas dos endereços eletrônicos das companhias na Internet, das entrevistas realizadas, assim como de relatórios de demonstrações financeiras divulgados publicamente.

Windsor Hotéis

A rede brasileira Windsor Hotéis persegue há 25 anos a estratégia de atender com qualidade superior o segmento de turismo de negócios. A empresa é tanto proprietária quanto administradora de seus empreendimentos e possui hotéis distribuídos em bairros turísticos estratégicos da cidade do Rio de Janeiro. A rede Windsor é um grupo de capital fechado e cada hotel tem uma composição societária diferente. Estima-se que o faturamento anual da rede gire em torno de $\mathrm{R} \$ 250$ milhões. Seu desempenho também pode ser verificado pelos seus planos de expansão na cidade, com a construção de, pelo menos, mais três hotéis, até 2016, indicando que o grupo está com capacidade de investimento, evidência de bom desempenho econômico-financeiro e estratégico.

Othon Hotéis

Fundada em 1943, a Othon pode ser considerada a primeira grande rede de hotéis do Brasil. A empresa atua com três modelos de negócios: propriedade (real state), contrato de gestão e franquia. A Othon é uma companhia de capital aberto e possui hotéis tanto no Brasil quanto em cidades como Lisboa, Paris e São Francisco. O faturamento bruto da Othon, em 2010, cresceu $12 \%$ em relação ao ano anterior. Entretanto, o prejuízo líquido da organização é da ordem de R $\$ 10$ milhões.

Brazil Hospitality Group

O BHG surgiu da fusão das empresas Latin America Hotels e InvestTur Brasil, realizada em fevereiro de 2009. Atualmente, o grupo, de capital aberto, forma uma das maiores redes hoteleiras do Brasil, com mais de 30 hotéis próprios e administrados. A empresa tem um contrato de exclusividade com o Golden Tulip Hospitality Group para uso de suas marcas na América do Sul, mas no momento a atuação está focada no território brasileiro. O BHG 
atingiu EBITDA de $\mathrm{R} \$ 10,8$ milhões, no terceiro trimestre de 2010, crescendo $124,3 \%$ em relação a 2009. No mesmo período, reportou $\mathrm{R} \$ 162$ milhões em caixa e a pretensão de investir R\$ 600 milhões para construir 40 hotéis no Brasil nos próximos cinco anos.

\subsubsection{Caracterização da estratégia do grupo estratégico pesquisado}

As informações recolhidas sugeriram fortemente que as três empresas aqui enfocadas compartilham um perfil semelhante de escopo e recursos e podem ser vistas como parte de um grupo estratégico, seguindo a definição de Cool e Schendel (1987).

Utilizando-se os dados coletados no questionário, nas entrevistas e nos documentos pesquisados, foi possível verificar que o grupo estratégico em foco persegue, nos termos de Mintzberg (1998), uma estratégia genérica de diferenciação por qualidade orientada para clientes de turismo, especialmente de negócios.

A acima afirmação é reforçada pelas seguintes declarações das empresas pesquisadas:

Nosso foco é a satisfação do cliente. Somos uma empresa familiar, com orientação total do principal executivo de focar nos serviços. É a maior preocupação dele. Não importa o custo, a rotina, o que importa é que o cliente saia satisfeito (Diretor de Marketing da rede Windsor em entrevista aos autores, 2011).

A gente tá num momento apontando para qualidade do serviço. Que vai ser um diferencial dentro de uma forte construção de marca [já realizada]. De três anos para cá estamos nesse foco de qualidade de serviço (Diretor Comercial da rede Othon em entrevista aos autores, 2011).

Com um olhar no futuro, trabalhar em equipe motivada e ética, com objetivos claros, utilizando padrões e critérios de nível internacional. Ser comercialmente agressivo, com eficiência em custos e excelência em serviços. Ter crescimento rápido e sustentável, com produtos bem localizados e atualizados, valorizando sempre a nossa maior estrela, "o Cliente" (Missão do BHG expressa em www.bhg.net, acesso em 2011). 
Antes de descrever as alianças mais relevantes das empresas estudadas, os resultados pertinentes aos fatores não-relacionais no nível da indústria são apresentados a seguir. Como as empresas fazem parte de um grupo estratégico, enfrentam implicações estratégicas semelhantes ao nível da indústria e podem, portanto, ser consideradas numa mesma rede de valor mais ampla.

\subsubsection{Implicações estratégicas dos fatores macro-ambientais e dos atores estratégicos}

As oportunidades e ameaças consideradas mais significativas dos fatores macro-ambientais, de acordo com Austin (1990), assim como dos atores estratégicos ao assumirem seus papeis de fornecedor, cliente, rivais (PORTER, 1980), ou complementors (BRANDENBURGER; NALEBUFF , 1997), são apresentados no Quadro 1.

Quadro 1 - Principais Implicações Estratégicas da Análise Tradicional

\begin{tabular}{|l|l|}
\hline \multicolumn{1}{|c|}{ Principais Oportunidades } & \multicolumn{1}{c|}{ Principais Ameaças } \\
\hline $\begin{array}{l}\text { A realização da Copa do Mundo de 2014 e das Olimpíadas de } \\
2016 \text { pode alavancar a demanda turística e gerar melhorias na } \\
\text { infra-estrutura turística do Brasil e da cidade do Rio de Janeiro; }\end{array}$ & $\begin{array}{l}\text { A infra-estrutura turística brasileira precisa de melhorias para } \\
\text { aumentar a sua competitividade; }\end{array}$ \\
\hline $\begin{array}{l}\text { As instituições governamentais, em função dos grandes eventos } \\
\text { que ocorrerão no Brasil, lançaram programas de financiamento } \\
\text { especiais para o turismo e fundos de investimento privados } \\
\text { começaram a atuar no setor, possibilitando a atração de novos } \\
\text { parceiros comerciais; }\end{array}$ & $\begin{array}{l}\text { A mão-de-obra é pouco qualificada e deficiente no conhecimento de } \\
\text { outros idiomas, o que representa uma contingência para o } \\
\text { crescimento do setor hoteleiro e das empresas na indústria do } \\
\text { turismo do país; }\end{array}$ \\
\hline $\begin{array}{l}\text { Os recursos naturais do Brasil e, especialmente, do Rio de } \\
\text { Janeiro são atrações turísticas e fontes de vantagem competitiva. }\end{array}$ & $\begin{array}{l}\text { A gestão não-sustentável dos recursos naturais do destino pode } \\
\text { comprometer uma de suas principais vantagens competitivas; }\end{array}$ \\
\hline $\begin{array}{l}\text { A estabilidade política do país aumenta a segurança e a } \\
\text { atratividade do destino turístico, assim como aumenta a confiança } \\
\text { dos investidores externos no Brasil e fortalece o mercado de } \\
\text { capitais p/ captação de recursos. }\end{array}$ & $\begin{array}{l}\text { Expandir a oferta hoteleira sem um plano efetivo para captação de } \\
\text { demanda para o periodo após a Copa do Mundo de Futebol e os } \\
\text { Jogos Olimpíadas que serão realizados no Brasil; }\end{array}$ \\
\hline $\begin{array}{l}\text { O aquecimento da economia brasileira faz aumentar as } \\
\text { oportunidades e a demanda por turismo de negócios. }\end{array}$ & $\begin{array}{l}\text { A burocracia para retirada do visto brasileiro, especialmente em } \\
\text { relação ao EUA, reduz a atratividade do destino, pois dificulta o } \\
\text { acesso e aumenta o inconveniente para os viajantes; }\end{array}$ \\
\hline $\begin{array}{l}\text { O grupo estratégico busca investir em aprimoramento tecnológico, } \\
\text { no país, o que os dá certa vantagem competitiva frente a } \\
\text { concorrentes menores. }\end{array}$ & $\begin{array}{l}\text { Para competir globalmente, o grupo estratégico precisa continuar } \\
\text { investir alto para ser capaz de alcançar concorrentes globais } \\
\text { experientes e tradicionais do setor hoteleiro. }\end{array}$ \\
\hline
\end{tabular}

Fonte: elaboração nossa.

\subsubsection{Alianças e outras ligações estratégicas do grupo estratégico pesquisado}

À luz da tipologia de ligações e da definição do conceito de alianças adotados, a pesquisa identificou que as redes hoteleiras possuiam relacionamentos relevantes com clientes, 
fornecedores, complementors, concorrentes, entidades governamentais e organizações representativas do setor/indústria. Apenas a rede Othon declarou ter ligação com substituitos e não foram identificadas relações com novos entrantes. Outro ator estratégico identificado como tendo ligações com as empresas estudadas, notadamente Windor e Othon, foram as organizações sem fins lucrativos focadas em desenvolvimento social, denomidadas ONGs.

De acordo com o questionário de percepções, a rede Windsor afirmou ter contratos de comercialização e acordos de permuta com os clientes. A Othon Hotéis, por sua vez, declarou, no questionário, estabelecer contratos/acordos de vendas/marketing em conjunto, de compartilhamento de informações/tecnologia e de comercialização. No caso do BHG, foram identificados acordos de co-desenvolvimento de produtos/serviços com os clientes (PR NEWSWIRE, 2010).

Com os fornecedores, a rede Windsor reportou, no questionário, estabelecer contratos de coprodução de serviços e produtos, assim como parcerias para ações de vendas e marketing em conjunto. Esses mesmos tipos de alianças foram identificados no caso do BHG (PR NEWSWIRE, 2010; BRASILTURIS JORNAL, 2010). Além desses, a rede Othon, também citou, por meio do questionário, os contratos de fornecimento de longo prazo.

Segundo os dados do questionário e da entrevista, a rede Othon estabelece contratos de gestão para operação de hotéis concorrentes. Além disso, os concorrentes também são parceiros da empresa em contratos de franquia da marca, de compra em conjunto, de promoção e propaganda e de permuta. No caso do BHG, o principal tipo de ligação identificado foi fusão/aquisição (www.bhg.net). Essa companhia claramente busca crescer por meio da aquisição de empreendimentos hoteleiros já existentes ou de contratos de gestão e, por isso, pode-se dizer que os concorrentes são seu principal parceiro. Outro dado que ratifica essa informação é o contrato de franquia de marcas que o grupo tem com o Golden Tulip Hospitality Group. A Windsor não citou, no questionário, os concorrentes como um de seus principais parceiros estratégicos. Entretanto, foi apurado, na entrevista, que são estabelecidos acordos para suprir a demanda de clientes no caso de lotação de seus hotéis e para a promoção do destino.

As organizações de classe são parceiras da rede Othon em contatos/acordos de compartilhamento de informações e tecnologia, de compra em conjunto e de permuta, segundo as respostas ao questionário. Além desses, a rede Windsor também citou, pelo 
questionário, contratos de co-produção de serviços e produtos, de vendas/ marketing em conjunto e parcerias de promoção e propaganda. No caso do BHG, foram verificadas também parceria para treinamento de equipe (ABIHONLINE, 2010; BRASILTURIS JORNAL, 2010). De acordo os dados das entrevistas, os acordos com as organizações representativas do setor e da indústria são, geralmente, para ações em feiras internacionais com o objetivo de aumentar a divulgação e a demanda turística do destino.

A rede Windsor afirmou, por meio das respostas ao questionário, que os mesmos tipos de ligações que ela desenvolve com as organizações de classe também são realizados com as entidades governamentais. A Othon, por sua vez, citou esse ator no questionário apenas como parceiro para acordos de permuta e o BHG apresentou ter acordos de financiamento com ele (ÉPOCA NEGÓCIOS, 2010).

Em relação aos complementors, o BHG se beneficia do contrato que tem com o grupo Golden Tulip para usufruir de parcerias com companhias aéreas, locadoras de veículos e operadoras de cartões de crédito (http://corporate.goldentulip.com). A rede Othon, por sua vez, informou pelo questionário que estabelece contatos/acordos de vendas e marketing em conjunto, de compartilhamento de informações/tecnologia, de fornecimento de longo prazo e de comercialização com esse ator estratégico. A Windsor reforçou na entrevista que não tem ligações estratégicas com complementors.

Apenas a rede Othon afirmou, por meio do questionário e da entrevista, ter ligações com substitutos, caracterizadas por contratos de franquia e de comercialização. No que concerne às ONGs, ela foram identificadas como um ator estratégico relevante para a rede de valor desta indústria, pois a responsabilidade socioambiental das empresas tem se mostrado cada vez mais importante no cenário competitivo global (NIDUMOLU; PRAHALAD; RANGASWAMI, 2009; Lubin \& Esty, 2010). Assim, as alianças com as ONGs podem ser consideradas estratégicas no sentido que agregam valor à competitividade das empresas.

Nesse sentido, aferiu-se, por meio dos dados documentais e das entrevistas, que tanto a rede Windsor quanto a Othon possuem acordos/parecerias de capital social e apoio/suporte com as ONGs. Ressalta-se que essas terminologias foram estabelecidas por esta pesquisa uma vez que não se encontrou, na literatura e nas referências adotadas, uma terminologia específica para esses casos. Os acordos de capital social referem-se a parcerias realizadas com entidades como o SEBRAE (Serviço Brasileiro de Apoio às Micro e Pequenas Empresas) para 
treinamento e absorção de mão-de-obra. Os acordos de apoio/suporte, em seu turno, são aqueles que as empresas estabelecem com as ONGs para ações pontuais, em geral caracterizadas por doações e sentido mais filantrópico. Não foram identificados esses tipos de relacionamentos para o $\mathrm{BHG}$.

Uma vez que a pesquisa identificou as redes hoteleiras Windsor, Othon e BHG como pertencentes ao mesmo grupo estratégico e, portanto, parte de uma rede de valor mais ampla, foi possível representar seus vínculos em uma macro ego-rede dentro desta rede de valor (MACEDO-SOARES; MENDONÇA, 2010). Conforme pode ser visto na Figura 1, no inicio deste artigo, a macro ego-rede é composta pelos atores estratégicos parceiros comuns às empresas estudadas - dispostos na elipse central. As principais ligações e alianças de cada empresa com os atores estratégicos identificados, caracterizados pelos diferentes tons de cinza (tipo de aliança), pela espessura das linhas (intensidade e força das conexões) e direção das setas (natureza das conexões) também estão visíveis no modelo conceitual apresentado.

A densidade da macro ego-rede pesquisada foi calculada com a fórmula de Knoke (KNOKE; YANG, 2008, p. 53), resultando 0,22 - o que pode ser considerado uma densidade moderada (SCOTT et. al., 2008). A centralidade dos atores - indicador de influência e poder exercido foi medida pelo número de ligações que esses possuem na rede (KNOKE; YANG, 2008; TIMUR; GETZ, 2008). Nesse sentido, a rede Othon pode ser considerada o ator mais central pesquisado, uma vez que apresentou o maior número de ligações em relação aos outros membros. Entretanto, Windsor e BHG não podem deixar de ser consideradas centrais pelas suas posições de liderança no setor em que atuam.

\subsubsection{Implicações estratégicas das alianças do grupo estratégico no nível da indústria}

A seguir, apresentamos as principais implicações estratégicas da macro ego-rede do grupo estratégico em questão, identificadas por meio dos dados coletados e consolidados. Para atribuir os resultados aos indicadores dos construtos relacionados à macro ego-rede, quantificaram-se os resultados individuais de cada empresa e aqueles que somados geraram as maiores médias foram considerados mais característicos do grupo estratégico analisado. Esses resultados são apresentados no Quadro 2. Nota-se que os construtos densidade e centralidade foram apresentados no item anterior. 
Quadro 2 - Características da Macro Ego-Rede Pesquisada

\begin{tabular}{|c|c|c|}
\hline Dimensão & Construtos & $\begin{array}{l}\text { Indicadores } \\
\text { (Resultado) }\end{array}$ \\
\hline \multirow{3}{*}{ Estrutura da Rede } & Densidade & Moderada \\
\hline & Escopo & Amplo / Global \\
\hline & Posição \& Centralidade & Central \\
\hline \multirow{3}{*}{ Membros da Rede } & Identidade/status da firma global & \multirow{2}{*}{$\begin{array}{c}\text { Forte; Sucesso; Ricos; } \\
\text { Global-Local }\end{array}$} \\
\hline & Identidade/status do parceiro & \\
\hline & $\begin{array}{l}\text { Acesso aos e volume dos } \\
\text { recursos dos parceiros globais }\end{array}$ & Fácil / Abundante \\
\hline \multirow{2}{*}{$\begin{array}{l}\text { Modalidade dos } \\
\text { laços }\end{array}$} & Força das conexões & Forte \\
\hline & Natureza dos laços & Colaborativa \\
\hline
\end{tabular}

Fonte: elaboração nossa.

A partir dos resultados acima, as principais implicações estratégicas das alianças do grupo estratégico em questão, no sentido de constituírem-se em oportunidades e ameaças, foram identificadas com base nas listas de referências do arcabouço de análise adotado (MACEDOSOARES, 2011). Nota-se que as características da macro ego-rede pesquisada representaram mais oportunidades que ameaças. Aquelas consideradas mais relevantes são reportadas abaixo:

- O perfil positivo apresentado pelos membros da macro ego-rede pesquisada pode influenciar a lucratividade da indústria focal.

- O fácil acesso aos recursos dos parceiros é uma oportunidade para o desenvolvimento de relações mais intensas e duradouras entre os membros da rede e a abundância dos volumes trocados representa uma oportunidade potencial para o desenvolvimento de inovações na indústria;

- As conexões fortes entre os membros da marco ego-rede são uma oportunidade para aumentar a produtividade do grupo estratégico e, assim, contribuir mais efetivamente para a competitividade do destino. Entretanto, corre-se o risco do grupo estratégico ficar amarrado em relações improdutivas; 
- As alianças colaborativas podem gerar resultados positivos para o destino no logo prazo, inclusive em relação ao seu desenvolvimento sustentável;

- Por meio das alianças colaborativas existentes, os membros da macro ego-rede podem influenciar políticas públicas e ações relacionadas ao turismo, visando o desenvolvimento socioeconômico da cidade enquanto destino turístico.

\section{Discussão dos Resultados}

Nesta seção, discutimos os principais resultados da pesquisa. Dessa forma, para atingir o objetivo de revelar as principais implicações estratégicas para os hotéis líderes do Rio de Janeiro sob a ótica relacional, fez-se uma comparação entre as oportunidades e ameaças identificadas anteriormente tanto na perspectiva tradicional e não relacional. A partir desta confrontação, as implicações estratégicas consideradas mais relevantes, no sentido de revelarem novos insights para a análise, são apresentadas no Quadro 3.

Quadro 3 - Confrontação das Implicações Estratégicas Tradicionais e Relacionais.

\begin{tabular}{|c|c|c|}
\hline \multicolumn{2}{|c|}{$\begin{array}{l}\text { dicional } \\
\text { Fatores Macroambientais / Atores da Rede de Valor }\end{array}$} & Implicação Resultante \\
\hline $\begin{array}{l}\text { 1) Ameaça Potencial } \\
\text { Caso os investimentos que estão sendo realizado na cidade não sejam } \\
\text { suficientes e/ou efetivos podem comprometer a atração de turistas ao } \\
\text { destino e será um risco para os grandes eventos que serão realizados. }\end{array}$ & $\begin{array}{l}\text { 1) Oportunidade Real } \\
\text { Por meio das alianças colaborativas existentes, o grupo estratégico pode } \\
\text { influenciar políticas públicas e ações relacionadas ao turismo, visando o } \\
\text { desenvolvimento econômico, social e ambiental do destino. }\end{array}$ & OPORTUNIDADE REAL \\
\hline $\begin{array}{l}\text { 2) Ameaça Real } \\
\text { A burocracia para retirada do visto brasileiro, especialmente em relação ao } \\
\text { EUA, principal país emissor, reduz a atratividade do destino, pois aumenta a } \\
\text { dificuldade para a entrada de turistas. }\end{array}$ & $\begin{array}{l}\text { 2) Oportunidade Real } \\
\text { As alianças colaborativas de escopo mais amplo e global permitem ao } \\
\text { grupo estratégico não ficar dependente de turistas de países com os } \\
\text { quais o Brasil aplica a reciprocidade em relação ao visto de entrada. }\end{array}$ & OPORTUNIDADE REAL \\
\hline $\begin{array}{l}\text { 3) Ameaça Potencial } \\
\text { Expandir a oferta hoteleira sem um plano efetivo para o pós eventos - Copa } \\
\text { do Mundo e Olimpíadas. }\end{array}$ & $\begin{array}{l}\text { 3) Oportunidade Real } \\
\text { As alianças colaborativas do grupo estratégico permitem uma melhoria } \\
\text { no serviço ofertado, abre novas possibilidades de negócios e aumenta a } \\
\text { visibilidade do destino de forma garantir a atratividade da demanda após } \\
\text { o grandes eventos no país. }\end{array}$ & OPORTUNIDADE REAL \\
\hline $\begin{array}{l}\text { 4) Ameaça Potencial } \\
\text { A gestão não-sustentável dos recursos naturais do destino pode } \\
\text { comprometer uma de suas principais vantagens competitivas. }\end{array}$ & $\begin{array}{l}\text { 4) Oportunidade Potencial } \\
\text { Ao assumir seu papel de liderança, o grupo estratégico pode contribuir } \\
\text { para aprimorar a eficiência da comunicação entre os membros da rede e } \\
\text { a difundir normas de conduta para as empresas do setor visando a } \\
\text { conservação do patrimônio natural do destino. }\end{array}$ & $\begin{array}{l}\text { OPORTUNIDADE } \\
\text { POTENCIAL }\end{array}$ \\
\hline $\begin{array}{l}\text { 5) Ameaça Real } \\
\text { A pouca qualificação e a deficiência, especialmente, no conhecimento de } \\
\text { outros idiomas para lidar com o público estrangeiro representa um séria } \\
\text { contingência para o crescimento do setor hoteleiro e das empresas na } \\
\text { indústria do turismo do país. }\end{array}$ & $\begin{array}{l}\text { 5) Oportunidade Real } \\
\text { As conexões fortes da macro-ego rede pesquisada podem contribuir para } \\
\text { aumentar a produtividade do grupo estratégico e, assim, contribuir mais } \\
\text { efetivamente para a competitividade do destino. }\end{array}$ & OPORTUNIDADE REAL \\
\hline $\begin{array}{l}\text { 6) Ameaça Real } \\
\text { Para competir globalmente, o grupo estratégico precisa continuar investir } \\
\text { alto para ser capaz de alcançar concorrentes globais experientes e } \\
\text { tradicionais do setor hoteleiro. }\end{array}$ & $\begin{array}{l}\text { 6) Oportunidade Potencial } \\
\text { As parcerias globais existentes podem ser reforçadas e estimuladas para } \\
\text { aumentar a quantidade de serviços prestados e para trazer para o grupo } \\
\text { estratégico processos padronizados globalmente que podem gerar } \\
\text { economias para ele chegar e manter uma posição competitiva no nível } \\
\text { dos concorrentes globais. }\end{array}$ & $\begin{array}{l}\text { OPORTUNIDADE } \\
\text { POTENCIAL }\end{array}$ \\
\hline $\begin{array}{l}\text { 7) Ameaça Potencial } \\
\text { Necessidade de grandes investimentos, de conhecimento do mercado, de } \\
\text { economias de escala e de localização geográfica são barreiras de entrada a } \\
\text { novos entrantes no setor hoteleiro, mas a oferta de investimento divulgada } \\
\text { devido aos grandes eventos, pode estimular a entrada de novos } \\
\text { concorrentes. }\end{array}$ & $\begin{array}{l}\text { 7) Oportunidade Real } \\
\text { A densidade da macro ego-rede pesquisada, em função da grande } \\
\text { quantidade de alianças estabelecidas entre os atores, representam } \\
\text { vantagens competitivas para o grupo estratégico e, consequentemente, } \\
\text { barreiras de entrada a novos entrantes. }\end{array}$ & OPORTUNIDADE REAL \\
\hline
\end{tabular}

Fonte: elaboração nossa. 
Pelo Quadro 3, é possível apreender que a maioria das ameaças reveladas pela análise tradicional dos fatores macro-ambientais e dos atores estratégicos é neutralizada pela visão estratégica relacional. A seguir comentamos brevemente cada um dos itens apresentados acima.

O item (1) diz respeito ao risco que o Rio de Janeiro corre, enquanto destino, de não conseguir cumprir com o planejamento de investimentos divulgado para modernizar sua estrutura turística e reduzir a violência urbana (ROCHA, 2010, LOUREIRO, 2009). Na ótica relacional, essa ameaça potencial é mitigada à luz da oportunidade real constituída pelos fortes laços do grupo estratégico com as entidades de classe e governamentais. Esses relacionamentos já vêm apresentando resultados nesse sentido como ocorreu com a participação do grupo na discussão sobre as alterações da legislação para a construção de novos hotéis na cidade (RÖTZSCH, 2009).

O item (2) está relacionado à queixa feita pelos executivos entrevistados a respeito dos entraves criados pelo governo brasileiro à entrada de turistas de países emissores de grande impacto no mercado, especialmente os Estados Unidos. Entretanto, ao adotarem uma visão estratégica relacional, esses dirigentes perceberão que as alianças globais por eles estabelecidas, especialmente com os grandes clientes globais que consolidam agências de viagem e fazem a distribuição da demanda mundial, minimizam o risco de dependência deles aos países com os quais o Brasil aplica os princípios de reciprocidade para emissão de visto.

O item (3) refere-se ao potencial risco das empresas hoteleiras, ao aproveitarem as oportunidades de financiamentos especiais criadas em função dos grandes eventos que serão sediados no Brasil, gerarem uma oferta maior do que a demanda prevista (GOLDBERG, 2010; ALMEIDA; NOGUEIRA, 2011). Entretanto, conforme reforça a literatura, os laços fortes e colaborativos do grupo estratégico pesquisado constituem uma oportunidade real para alavancar a divulgação do destino de forma a manter um nível superior de demanda, gerando novas oportunidades de negócios, como outros eventos que ocorrerão no país como a Conferência das Nações Unidas sobre Desenvolvimento Sustentável, em 2012.

O item (4) trata da ameaça potencial da não preservação de uma das maiores vantagens competitivas do destino Rio de Janeiro, que é o seu patrimônio natural. As empresas do grupo estratégico pesquisado demonstram, em suas páginas institucionais na Internet, que têm políticas e realizam ações de redução de impactos ambientais em suas operações. Logo, pela 
visão relacional, ao assumirem os seus papéis de liderança na rede da indústria do turismo da cidade, o grupo estudado pode potencialmente contribuir para aprimorar e difundir normas de conduta para as empresas do setor visando à conservação do meio-ambiente do destino, neutralizando assim a ameaça potencial acima mencionada.

O Item (5) engloba a questão da falta de capacitação da mão-de-obra brasileira, especialmente no conhecimento de outros idiomas, que limita as empresas do setor hoteleiro, pois é uma contingência para sua expansão. Por meio das alianças colaborativas, o grupo estratégico minimiza essa ameaça ao desenvolver junto com entidades governamentais e de classe ligadas ao turismo programas de capacitação como cursos técnicos e de idiomas (ABIHONLINE, 2010).

No item (6), a capacidade do grupo estratégico de competir globalmente é percebida como uma ameaça real devido às empresas não apresentarem uma postura de expansão global clara. No entanto, o fato das empresas terem alianças globais minimiza essa ameaça uma vez que os recursos trazidos por essas parcerias, como processos padronizados globalmente, conhecimento de mercados e divulgação das marcas, podem gerar economias na eventual busca do grupo por conquistar e manter uma posição competitiva no nível dos concorrentes globais.

O item (7) apresenta a ameaça potencial de novos entrantes no setor hoteleiro pela visão tradicional, que é mitigada quando se adota a perspectiva relacional. Os novos entrantes constituem uma ameaça potencial, na análise tradicional, devido à oferta de investimentos para o setor hoteleiro em função dos grandes eventos que ocorrerão no Brasil, minimizando a necessidade de grandes investimentos de capital que é uma forte barreira de entrada desse setor. Na perspectiva relacional, a densidade da rede de alianças do grupo estratégico cria barreiras que dificultam a entrada de novos players no curto prazo e assim neutralizam a ameaça destes.

Os resultados discutidos nesta seção sugerem fortemente que o grupo estratégico pesquisado tem condições - por seu posicionamento competitivo, desempenho e relacionamentos estratégicos - de aproveitar as diversas oportunidades reveladas pela análise relacional e, assim, contribuir mais efetivamente para o desenvolvimento do destino em que atuam por meio da indústria do turismo. 


\section{Considerações Finais}

Este artigo apresentou os resultados de um estudo de caso múltiplo sobre os hotéis líderes da cidade do Rio de Janeiro com perfil de negócios e eventos. O estudo buscou identificar e analisar as implicações estratégicas - oportunidade e ameaças - das alianças estabelecidas pelo grupo estratégico pesquisado, utilizando um arcabouço de análise estratégica relacional já testado em diversas indústrias e aplicado pela primeira vez na indústria do turismo.

Os resultados mostraram que a adoção de uma perspectiva relacional por parte dos executivos dos hotéis contribui às suas analises estratégicas ao permitir capturar novos insights para o processo de tomada de decisão que mudam o conjunto de resultados da análise. A investigação revelou também que a maioria das ameaças identificadas pela análise tradicional, ou seja, geradas por fatores macro-ambientais ou pelos atores estratégicos ao desempenhar seus papéis tradicionais, é neutralizada quando se adota uma visão relacional, que ao levar em conta as características das alianças, na perspectiva da rede que estas configuram, permite uma compreensão mais apurada do contexto competitivo da indústria. Além de evidenciar a importância de adotar uma perspectiva relacional, a pesquisa enfim contribuiu para mostrar como hotéis podem na prática, com auxílio do arcabouço adotado, realizar análises estratégicas mais completas por essa perspectiva.

Esta pesquisa enfrentou algumas limitações que podem ser consideradas oportunidades a investigações futuras. A primeira deve-se ao fato da análise ter sido feita apenas no nível da indústria. Nesse sentido, para apurar mais profundamente se o grupo estratégico tem condições de assumir o seu papel de liderança na macro ego-rede pesquisada e, assim, de fato, aproveitar as oportunidades reveladas, é preciso complementar esse estudo com uma análise no nível das empresas para a identificação de suas forças e fraquezas. Outra limitação diz respeito a esta pesquisa apresentar um recorte de um momento específico. Por isso, para acompanhar o desempenho do grupo estratégico e sua evolução ao longo do tempo, pesquisas futuras devem ser realizadas, em especial após os grandes eventos que ocorrerão no Brasil, para verificar se o destino turístico alavancou o seu potencial competitivo ao aproveitar as oportunidades aqui identificadas. 


\section{Referências}

ABIHONLINE. Olá Turista: apoio total da hotelaria carioca. Boletim Informativo Online da ABIH-RJ, n. $70,2010$.

ABIH-RJ/FECOMÉRCIO. Anuário Estatístico ABIH-RJ, 2009

ALMEIDA, C.; NOGUEIRA, D. A volta por Cima. O Globo, 12 de Janeiro de 2011.

ALVARENGA, D. Classe C já troca casa de parente por hotel, diz executivo da Accor. G1, São Paulo, 2011

AUSTIN, J. E. Managing in Developing Countries: Strategic Analysis and Operating Techniques. New York: The Free Press, 1990.

AYOUN, B.; MOREO, P. J. Does national culture affect hotel managers' approach to business strategy? International Journal of Contemporary Hospitality Management, v. 20 n. 1, 2008.

BARTLETT, C. A.; GHOSHAL, S. Managing across borders: The transnational solution. Cambridge: Harvard Business School Press, $2^{\text {nd }}$ Ed., 1998.

BRANDENBURGER, A. M.; NALEBUFF, B. J. Co-opetition. New York: Dobleday, 1996.

BRASILTURIS JORNAL. BHG prepara festa para agentes de viagem. Informativo da Indústria Turística Brasileira, 30/11/2010.

CHEN, J. J.; DIMOU, I. Expansion strategy of international hotel firms. Journal of Business Research, $58,2005$.

CLAVER-CORTÉS, E.; MOLINA-AZORÍN, J. F.; PEREIRA-MOLINER, J. Competitiveness in Mass Tourism. Annals of Tourism Research, vol. 34, n. 3, 2007.

CONTRACTOR, J. F.; KUNDU, K. S. Modal choice in the world of alliances: analyzing organizational forms in the international hotel sector. Journal of International Business Studies, 29(2), 1998.

CONTRACTOR, F. J.; LORANGE, P. Why Should Firms Cooperate? The Strategy and Economics Basis for Cooperative Ventures. In: Cooperative Strategies is International Business. Lexington (MA): Lexington Books, 1998.

COOL, K.; SCHENDEL, D. Strategic Group Formation and Performance: The Case of the U.S. Pharmaceutical Industry. Management Science, n. 33 (9), 1987.

DREDGE, D. Policy networks and the local organization of tourism. Tourism Management, 27, 2006.

EISENHARDT, K. M.; GRAEBNER, M. E. Theory Building from Cases: Opportunities and Challenges. Academy of Management Journal, vol. 50, n. 1, 2007.

ERKUS-ÖZTÜRK, H. The role of cluster types and firm size in designing the level of network relations: The experience of the Antalya tourism region. Tourism Management, n. 30, 2009. 
ÉPOCA NEGÓCIOS. BHG investirá R\$ 600 milhões para construir 40 hotéis no Brasil. Disponível em: < http://epocanegocios.globo.com>. Acesso em: 22 nov. 2010.

EXAME.COM. BHG, da GP, planeja ser a BR Malls da hotelaria. Disponível em: $<$ http://exame.abril.com.br>. Acesso em: 26 jan. 2010.

FAHEY, L.; RANDALL, R. M. Learning from the Future: Competitive foresight Scenarios. New York: John Willey \& Sons, 1998.

GALASKIEWICZ, J.; ZAHEER, A. Networks of Competitive Advantage. Research in the Sociology of Organizations, Jai Press Inc, vol. 16, 1999.

GOLDBERG, S. Linhas de Crédito vão Facilitar os Investimentos. In: Valor Especial Turismo, 2010.

GOMES, J. C. (ORG.) Caderno de Turismo do Estado do Rio de Janeiro: passaporte para o desenvolvimento do Estado. Rio de Janeiro: Fecomércio, 2010.

GULATI, R. Alliances and Networks. Strategic Management Journal, vol. 19, 1998.

GULATI, R; NOHRIA, N.; ZAHEER, A. Strategic Networks. Strategic Management Journal, vol. 21, 2000.

HALINEN, A.; TÖRNOOS, J-A. Using case methods in the study of contemporary business networks. Journal of Business Research, vol. 58, 2005.

HARZING, A-W. Empirical Analysis and Extension of the Bartlett and Ghoshal Typology of Multinational Companies. Journal of International Business Studies, vol. 31, n. 1, 2000.

HITT, M. A.; IRELAND, R. D.; HOSKISSON, R. E. Strategic Management: Competitiveness and Globalization. Mason, OH: South-Western Cengage Learning, 8th Ed, 2009.

INSTITUTO BRASILEIRO DE GEOGRAFIA E ESTATÍSTICA - IBGE. Economia do Turismo: uma perspectiva macroeconômica 2000-2005. Estudos e Pesquisas IBGE, 2008.

JOHNSON, C.; VANETTI, M. Locational Strategies of International Hotel Chains. Annals of Tourism Research, vol. 32, n. 4, 2005.

JONES LANG LASALLE HOTELS. Lodging industry in numbers Brazil 2010. Brasília, Brazil., 2010 .

KNOKE, D.; YANG, S. Social Network Analysis. $2^{\text {nd }}$ ed. Sage Publications Inc, 2008.

LOUREIRO, C. Ministro anuncia repasse imediato de verbas em segurança e mais UPPs. http://g1.globo.com, 27/10/2009.

LUBIN, D. A.; ESTY, D. C. The Sustainability Imperative: Lessons for Leaders from Previous GameChanging Megatrends. Harvard Business Review, May, 2010.

MACEDO-SOARES, T. D. V. A. Ensuring Dynamic Strategic Fit of Firms that Compete Globally in Alliances and Networks: Proposing the Global SNA - Strategic Network Analysis - Framework. Revista de Administração Pública-RAP, v. 45, n. 1, 2011. 
MACEDO-SOARES, T. D. V. A. Strategic Alliances and Networks: Conceptual Tools for Strategic Assessments. In: Proceedings of GBATA conference, Rome, 2002.

MACEDO-SOARES, T. D. V. A.; MENDONÇA, A. P. G. Strategic Implications of Alliances and Other Linkages of Leading Telecom Operators in Brazil: Network and International Perspectives. Latin American Business Review, n. 11, 2010.

MARCH, R.; WILKINSON, I. Conceptual Tools for Evaluating Tourism Partnerships. Tourism Management, n. 30, 2009.

MARTÍNEZ, E. E. V.; ESQUIVEL, M. H. Importancia de la Internacionalización de la Empresa Hotelera en el Valle de Toluca. Estudios \& Perspectivas en Turismo, vol. 15, 2006.

MINTZBERG, H. Generic Strategies: toward a comprehensive framework. Advances in Strategic Management, vol.5, 1998.

MINISTÉRIO DO TURISMO BRASIL - MTUR. Estatísticas Básicas de Turismo. Brasília, Brasil, 2010.

MINISTÉRIO DO TURISMO BRASIL - MTUR. Plano Nacional de Turismo 2007-2010. Brasília, Brasil, 2007.

NIDUMOLU, R.; PRAHALAD, C. K.; RANGASWAMI, M. R. Why Sustainability is Now the Key Driver for Innovation. Harvard Business Review, September, 2009.

NOHIA, N.; GARCIA-PONT, C. Global Strategic Linkages and Industry Structure. Strategic Management Journal, n. 12. 1991.

NOVELLI, M.; SCHIMITZ, B.; SPENCER, T. Networks, Clusters and Innovation in tourism: A UK Experience. Tourism Management, n. 27, 2006.

PANSIRI, J. The effects of characteristics of partners on strategic alliance performance in the SME dominated travel sector. Tourism Management, n. 29, 2008.

PARISE, S. The Effects of Resource Exchange and Partner Roles on Alliance Performance. Ph.D Thesis School of Management, Boston University, 2000.

PORTER, M. E. Competitive Strategy. New York: The Free Press, 1980.

PR NEWSWIRE. O grupo Golden Tulip lança Central de Reservas e plataforma de distribuição de "próxima geração": Goldres3. Http://ipoom.com, 8/10/2010.

ROCHA, C. Ideia de Aparts na Zona Portuária Anima Mercado. O Globo, 19/05/2010.

RÖTZSCH, R. Rio de Janeiro cria incentivos por novos hotéis para Copa e Jogos Olímpicos. Folha.com, 26/11/2010.

SCOTT, N.; BAGGIO, R.; COOPER, C. Network Analysis and Tourism: from theory to practice. Channel View Publications, 2008.

TIMUR, S.; GETZ, D. A network perspective on managing stakeholders for sustainable urban tourism. International Journal of Contemporary Hospitality Management, vol. 20, n. 4, 2008. 
TREMBLAY, P. The Economic Organization of Tourism. Annals of Tourism Research, vol. 5, 1998.

WANG, Y.; FESENMAIER, D.R. Collaborative destination marketing: A case study of Elkhart county, Indiana. Tourism Management, n. 28, 2007.

WANG, Y.; KRAKOVER, S. Destination Marketing: Competition, Cooperation or coopetition? International Journal of Contemporary Hospitality Management, vol. 20, n. 2, 2008.

WORLD TOURISM ORGANIZATION - UNWTO Tourism Highlights. 2010. Disponível em: $<$ http://www.unwto.org $>$. Acesso em: 2010.

YIN, R. K. Estudo de caso: planejamento e método. $3^{\text {a }}$ ed. Porto Alegre: Brookman, 2005.

Recebido em: 19/10/2011

Aprovado em: 25/02/2012 